International Journal of Food Microbiology

December 2018, Volume 286 Pages 1-5

http://dx.doi.org/10.1016/i.ijfoodmicro.2018.07.016

http://archimer.ifremer.fr/doc/00450/56140/

(c) 2018 Published by Elsevier B.V.

\title{
Improving the efficacy of sewage treatment decreases norovirus contamination in oysters
}

\author{
Schaeffer Julien ${ }^{1}$, Treguier Cathy ${ }^{2}$, Piquet Jean-Come ${ }^{1}$, Gachelin Sonia ${ }^{3}$, \\ Cochennec-Laureau Nathalie ${ }^{2}$, Le Saux Jean-Claude ${ }^{1}$, Garry Pascal ${ }^{1}$, Le Guyader Soizick ${ }^{1,}$
}

${ }^{1}$ Ifremer, Laboratoire de Microbiologie, LSEM/SG2M, Nantes, France

2 Ifremer, Laboratoire Environnement Ressources MPL, la Trinité sur Mer, France

${ }^{3}$ Comité Régional Conchylicole de Bretagne sud, Auray, France

* Corresponding author : Soizick Le Guyader, email address : sleguyad@ifremer.fr

\begin{abstract}
:
As human population increases worldwide, water quality will become increasingly problematic, and food consumed raw may be of higher risk. This is already evident for oysters grown in coastal areas - despite regulations based on bacterial indicators, oysters are still implicated in food-borne outbreaks worldwide. The pathogens most frequently detected are human noroviruses, which are shed at high concentrations in human excreta and are very resistant to environmental conditions. Sewage treatment plants usually apply a variety of steps such as activated sludge treatment, chlorine or UV disinfection to eliminate contaminants, these processes have variable efficacy. This study demonstrates the impact of replacing an old lagoon-based sewage treatment plant with a new membrane bioreactor sewage treatment plant on human norovirus levels in treated sewage and oysters. While comparable norovirus concentrations were detected in the influent samples, a clear difference was observed in effluent quality, as norovirus was only detected in one sample after treatment in the new membrane bioreactor system, confirming the efficiency of such technology. As a direct impact, oysters located close to the membrane bioreactor sewage outfall were less frequently contaminated by norovirus, and showed lower concentrations compared to the first period of the study when they were exposed to sewage effluent from the lagoon outfall. Shellfish located upstream showed comparable contamination levels suggesting that there are also other sources of norovirus contamination in the estuary. Considering the health benefits of shellfish consumption, improving wastewater quality will make an important contribution to enhancing the safety of shellfish and international food
\end{abstract}




\section{Highlights}

- Old lagoon sewage treatment plant is inefficient in eliminating human norovirus. Membrane bioreactor treatment plant improves the microbiological quality of effluent. $>$ Oyster contamination by norovirus can be prevented by improving sewage treatment. Several factors may contribute to water contamination in an estuary. Lowering human sewage input in surface waters will be beneficial for international food security.

Keywords : Norovirus, Shellfish safety, Sewage treatment, Coastal water quality 


\section{Introduction}

Contaminated food and water is a major pathway for the transmission of infectious diseases and poses a global health issue, with viruses being one of the most frequently reported infectious agents (Havelaar et al., 2015). Human effluent contains a large variety of microbial pathogens that are derived from the human gut, such as enteric viruses that cause gastroenteritis or hepatitis. These viruses are excreted in the stools and vomitus of infected individuals at high concentrations, thus wastewater effluent is a major source of viruses in environmental waterways ( Monedero et al., 2018; Newton et al.,2015;). Increasing viral elimination during sewage treatment should lead to improvements in effluent quality and help to prevent further distribution and transmission of viruses through the food chain, this is especially important for foods that are consumed raw (Uyttendaele et al., 2015). For example, the association between raw shellfish consumption and human viral diseases was recognized around 40 years ago (Murphy et al.,1979).

The viral pathogens most frequently responsible for shellfish-borne illness outbreaks are human noroviruses (HuNoV) (Yu et al., 2015). Within the Caliciviridae family, HuNoVs are non-enveloped viruses, with a single-stranded positive-sense RNA genome. They are classified into seven genogroups (G), three of which infect humans, GI, GII and GIV (De Graaf et al., 2016). Infection induces acute gastroenteritis with vomiting and diarrhea, with clinical symptoms lasting for 2 to 3 days and a large quantity of progeny viruses are shed in the feces of infected people for several weeks (Atmar et al.,2014; Teunis et al., 2015). Asymptomatic people can also shed high concentrations of viral particles in their stools, thus during gastroenteritis outbreaks large numbers of viral particles may be discharged into water bodies through the release of untreated or partially treated sewage (Sano et al., 2016; Teunis et al., 2015).

Sewage treatment plants usually apply a combined process to reduce contaminant levels, which may include physical (e.g; settlement), biological (e.g. activated sludge) and chemical steps (e.g. chlorination) (Sano et al.,2016). The efficacy of each sewage treatment process (e.g. waste stabilization ponds), activated sludge or membrane bio-reactors) in removing viral contaminants varies, as does the impact on the coastal environment (Miura et al., 2018, Wang et al., 2018). 
The objective of this study was to evaluate the impact of replacing an old sewage treatment plant with waste stabilization ponds (lagoon treatment) with a new sewage treatment plant with a membrane bioreactor on HuNoV levels in oysters that were strategically placed in the area for this study.

\section{Materials and Methods}

\section{Study site.}

The estuary is located in south western France (Brittany), and it contains a sewage treatment plant (STP) in close proximity to shellfish beds (Figure 1). Before October 2013, the STP was composed of a gravity-fed lagoon treatment system which had a series of 3 ponds (also called a waste stabilization pond system). During 2013, a new STP with membrane bioreactor treatment (MBR) was built adjacent to the old STP and it was commissioned in October 2013.

For the study, oyster batches (around 500 individual oysters each) were placed on oyster tables $(50 \mathrm{~cm}$ above the bottom of the estuary) at selected points around the STP outfall: three points (A, B, C) were located upstream (around 1.5 to $2 \mathrm{~km}$ ) of the outfall, and two sampling points (D, E) were located downstream (from 0.2 to $1 \mathrm{~km}$ ) (Figure 1).

\section{Sample collection.}

Influent and effluent samples were collected bi-monthly (monthly during the summer months) over a one year period from the old lagoon STP, and over a seven month period from the new STP. Automatic samplers collected 24-h composite samples with a total volume of 1-liter. Oyster samples were collected the following day, from the five sampling points. The two periods for collecting the oyster samples (collection at low tide) were long enough and were over the same time period each the year (including winter and spring time), thus ensuring that other potential impacts from factors such as the tide, rain and wind were tacitly accounted for in the experimental design. All samples were transported to the laboratory on ice and processed within $24 \mathrm{~h}$ of collection. A total of 60 wastewater samples (30 influent and 30 effluent) and 148 oyster samples were collected. 


\section{Sample processing.}

Effluent samples were concentrated from $1 \mathrm{~L}$ to $40 \mathrm{~mL}$ with cross-flow ultrafiltration (Vivaflow 50, Sartorius, Germany) (Sima et al., 2011). Mengovirus (MgV) $\left(2 \times 10^{6}\right.$ RNA copies) was added to the effluent concentrate and to $40-\mathrm{mL}$ of un-concentrated influent samples and then concentrated using a polyethylene glycol (PEG) precipitation method (Sima et al., 2011). The PEG pellet was suspended in $1 \mathrm{~mL}$ of deionized distilled water (DDW) with a vortex mixer.

For oyster samples, 10 individuals were shucked, weighed, and the digestive tissues (DTs) dissected. $\operatorname{MgV}\left(2 \times 10^{6}\right.$ RNA copies $)$ was added to each DT sample $(2 \mathrm{~g})$ before incubation with $2 \mathrm{~mL}$ of proteinase K solution (ISO/TS 15216-1, 2017).

\section{Nucleic acid extractions.}

For wastewater samples, the re-suspended PEG pellet was mixed with $2 \mathrm{~mL}$ of lysis buffer (bioMérieux, Lyon France) (Sima et al., 2011). For oyster samples, after the proteinase K treatment the entire supernatant (around $3 \mathrm{~mL}$ ) was mixed with $10 \mathrm{~mL}$ of lysis buffer (Le Mennec et al., 2017). Both mixtures were incubated for $10 \mathrm{~min}$ at room temperature, and after a brief centrifugation to eliminate solid particles (if needed), 50 or $150 \mu \mathrm{L}$ of paramagnetic silica was added (depending on the volume of lysis buffer), and further incubated for $10 \mathrm{~min}$ at room temperature. The purification steps were performed with an automatic easyMAG extractor (bioMérieux) and the NucliSENS kit (bioMérieux). Nucleic acids (NAs) were recovered in $100 \mu \mathrm{L}$ of elution buffer (bioMérieux) and analyzed immediately or kept frozen $\left(-80^{\circ} \mathrm{C}\right)$. The $\mathrm{MgV}$ control was also extracted using the NucliSENS kit.

\section{Primers, probes and real time RT-PCR ( $r$ RT-PCR)}

The primers and probes used for $\mathrm{MgV}$ and NoV (GI, GII and GIV) detection were previously described (ISO/TS 15216-1, 2017; Miura et al., 2013). The $r$ RT-PCR was carried out with the UltraSense One-step quantitative RT-PCR system (Life Technologies, France) on a Mx3000P QPCR System (Agilent Technologies, France). For shellfish, after checking for inhibition by performing $\mathrm{MgV}$ amplification on $5 \mu \mathrm{L}$ of neat (undiluted) NA and $5 \mu \mathrm{L}$ of a ten-fold dilution, HuNoV detection was performed using $5 \mu \mathrm{l}$ of neat NA per well (final volume of $25 \mu \mathrm{l}$ ) in triplicate. For wastewater 
samples, $5 \mu \mathrm{l}$ of neat NA and $5 \mu \mathrm{L}$ of a ten-fold dilution, were used both for $\mathrm{MgV}$ amplification and for $\mathrm{HuNoV}$ detection. A standard curve, using a plasmid containing nucleotides 4191 to 5863 of the GII.4 Houston virus (Genbank EU310927), was included in each run.

\section{$r$ RT-PCR controls and quantification.}

Samples considered positive, had to yield a cycle threshold $\left(\mathrm{C}_{\mathrm{T}}\right)$ value of $\leq 41$, and only samples with a $\mathrm{C}_{\mathrm{T}}$ value of $\leq 39$ were quantified. Two negative amplification controls (sterile RNase-free water) were included in each amplification series and filter tips and dedicated rooms were used to prevent false-positives.

- Extraction efficiency: After extraction of samples seeded with $\mathrm{MgV}$, amplification was performed and the $\mathrm{C}_{\mathrm{T}}$ values of samples (neat and ten-fold dilutions) were compared to the $\mathrm{C}_{\mathrm{T}}$ value of the positive control used in the extraction series, and to the standard curve made by end point dilution. This difference $\left(\Delta \mathrm{C}_{\mathrm{T}}\right)$ was used to determine the extraction efficiency and was expressed as a percentage for each sample (Sima et al., 2011). The difference was also used to verify the absence of inhibitors. Only samples with extraction efficiencies above $1 \%$ were considered for quantification.

- Standard curve validation: After completion of all $r$ RT-PCR runs, all standard curves were compared and quality criteria were applied (Afnor, 2011). Only runs in which the standard curves had amplification efficiencies of 85 to $110 \%$ were retained.

- Quantification: The $\mathrm{C}_{\mathrm{T}}$ values obtained for each sample extract were averaged and the number of RNA copies in each positive sample extract was back-calculated based on the volume of NA analyzed and expressed per g of DT or L of wastewater. Concentrations obtained for each extract were calculated separately and values obtained were used to calculate the geometric mean concentration (GMC) for each sample.

\section{Statistical analysis.}

To compare concentrations between sample types, the Student's $t$ test was performed on Log transformed values using Prism 5 (GraphPas Software, Inc). 


\section{Results.}

\section{Extraction efficiency and quality controls.}

The mean extraction efficiency for influent samples was $6.1 \%$ before October 2013 and $6.2 \%$ after October 2013, and 6.5\% before October 2013 and 29.9\% after October 2013 for effluent samples (Table 1). No inhibition was detected for 56 samples, but despite repeated extractions, three influent samples and one effluent sample were inhibitory (two influent samples and one effluent sample collected before October 2013, and one influent sample collected after October 2013). For these four samples, data analysis was performed using the results from the NA that was diluted 10-fold. For oyster samples, the mean extraction efficiency was comparable from sites upstream and downstream of the outfall for both time periods considered. None of the oyster extracts were inhibited.

\section{Wastewater samples.}

A total of 60 wastewater samples were analyzed over 19 months (from October 2012 to May 2014). Before October 2013, all except one influent sample were positive for HuNoV. For the same period, HuNoV's were detected in $71 \%$ of effluent samples, the GMC being 10 times lower compared to influent samples (Table 1). After October 2013, 11 out of 13 influent samples were positive for HuNoV and only one effluent sample was positive, showing the efficiency of the new sewage treatment plant. The GMC of HuNoV in influent samples collected before and after October 2013 were comparable and showed no statistical difference $(P=0.1229)$.

\section{Oyster samples.}

A total of 148 samples were analyzed over the same period of time as the wastewater samples (19 months), 85 samples were negative for $\mathrm{HuNoV}$ and 63 samples were positive (Table 1). Before October 2013, a higher proportion of samples were positive for HuNoV (52\%) compared to the second period of the study (30\%). This difference was emphasized when comparing the upstream and downstream sites for the two periods of the study: $49 \%$ and $56 \%$ of samples from upstream and downstream sites respectively, were positive for HuNoV before October 2013; However, after October 2013 , only $36 \%$ and $29 \%$ were positive from upstream and downstream sites respectively. No 
statistical difference was found when comparing the GMC of $\mathrm{HuNoV}$ in oyster samples collected from upstream and downstream sites before October $2013(P=0.46)$, or after October $2013(P=0.15)$ (Table 1). However, when comparing the two periods of the study, the HuNoV levels in oyster samples collected downstream were significantly lower after October 2013 compared to samples collected from the same sites before October $2013(P<0.01)$ (Table 1).

\section{Discussion}

Clean irrigation water is considered a critical factor for fresh produce (Uyttendaele et al., 2015). Similarly, reducing human sewage contamination in coastal areas is a key issue for improving shellfish quality and protecting consumers. Indeed, the basic physiological activities that oysters perform to respire and feed means that they filter large volumes of water and concentrate particles within their digestive tracts, including any contaminants that may be present in the surrounding seawater. The need to improve depuration for oysters grown in poor quality waters was recognized in studies conducted more than a century ago (Wells, 1916). Food safety regulations, which are based on bacterial indicators in shellfish tissues (European regulation 54/2004/EU) or waters (United States National Shellfish Sanitation Program), have significantly decreased the number of bacterial outbreaks among consumers, but virus-related gastroenteritis and hepatitis outbreaks persist (Yu et al., 2015). The regulations specify that shellfish harvested from contaminated areas, need to be subjected to postharvest treatments such as depuration, relaying or cooking. While depuration is effective for most bacterial contaminants, it is inefficient for viruses, and was not intended for purifying grossly polluted shellfish (Richards et al., 1988). A recent review confirms that viral depuration of shellfish is very slow and many viral illness outbreaks have been linked to depurated shellfish (McLeod et al., 2017). This may be partly explained by the specific binding of $\mathrm{HuNoV}$ to the oyster digestive tract through an A-like carbohydrate structure (which is indistinguishable from human blood group A antigen), other ligands such as sialic acids, and also through ionic bonding (Di Girolamo et al., 1977; Le Guyader et al., 2006; Tian et al., 2007). To avoid the marketing of virus-contaminated shellfish, end-product testing using molecular methods is one risk management option (ISO/TS 15216-1, 2017), however this approach is difficult, because in addition to HuNoV's, there may be a variety of other human enteric 
viruses present in the shellfish, such as hepatitis A virus, enterovirus, rotavirus or sapovirus ( Boxman et al., 2016; Kittigul et al., 2014; McLeod et al., 2009; Polo et al., 2015; Ueki et al., 2010) - testing for such a diversity of viruses presents both logistic and economic challenges. The plethora of viruses detected in shellfish is linked to the high diversity of viruses in human sewage, reflecting the microbiome of the local population, and thereby potentially favoring the dispersion of emerging viruses (Bisseux et al., 2018; Geoghegan et al.,2016; Newton et al., 2015). Therefore, it is of critical importance to prevent shellfish contamination by avoiding contact with sewage-contaminated seawater. One option is to design buffer zones around sewage outfalls, whereby shellfish harvesting is prohibited, as already proposed in some guidelines (European Commission, 2017; FDA, 2013). However, if improvements to wastewater quality are not made, this approach could mean that there is an increase in prohibited zones, because the human population around coastal areas is increasing concomitantly with the heightened demands for shellfish. Additionally, other factors can also contribute to viral contamination of shellfish, such as water temperature, rainfall, currents, salinity, and wind (Campos et al., 2017; Maalouf et al., 2010; Wang and Deng, 2016).

Sewage treatment can be performed using different technologies with varying efficiencies (Gerba et al., 2018; Sano et al., 2016; Wang et et al., 2018). The MBR process has been demonstrated to be one of the most efficient for the elimination of small particles such as viruses (Miura et al., 2015; Sima et al., 2011). In our study, with comparable HuNoV concentrations in the influent, a clear difference was observed in effluent quality, as only one sample was positive after MBR treatment, confirming the efficiency of such technology. As a direct impact, shellfish located close to the MBR outfall were less frequently contaminated by HuNoVs, and more interestingly showed statistically lower HuNoV concentrations compared to the first period of the study when they were exposed to the lagoon outfall. On the other hand, no impact was observed for oyster samples located upstream of the outfall, suggesting other viral inputs may be at play. Estuaries are complex environments with various factors that influence the presence and concentration of micro-organisms, including persistence in sediments, behavior in seawater, tides and currents (Pommepuy et al., 2005). Direct discharge of treated or untreated sewage effluent, unintentional discharges by urban dwellings, rural run-off, waste input from boats, and fresh water discharges into tributary rivers, also contribute to coastal contamination (La 
Rosa et al., 2017). It is clear that contamination of shellfish beds can occur through various pathways, not just from STP effluent, and the results of this study highlight that further investigations are needed to decrease viral input into the upper part of the estuary from other unknown sources.

\section{Conclusions}

Human microbial contamination in coastal areas can be proactively managed and the impacts on shellfish quality reduced. Commissioning efficient STPs that use MBR technology and accurate tracking work to pinpoint other sources of viral contamination in coastal areas will help to improve shellfish quality and also bathing water quality. Considering the health benefits of shellfish consumption, the increasing global population (with the population expected to reach 9.7 billion by 2050) and associated heightened food requirements, all contributions to lowering human sewage input will be beneficial for international food security (Venugopal and Gopakumar, 2018).

\section{Acknowledgments}

We are very grateful to local oyster producers and the sewage treatment plant staff (SAUR, Vannes, France) for their assistance during the study. We acknowledge the help of Catherine McLeod (Seafood Safety Assessment) for critical review of the manuscript and Alice Mellor for proof reading. This study was supported by a European Grant 'Fond Européen de la Pêche (FEP)' and by Conseil Départemental du Morbihan, France.

\section{References}

Afnor. 2011. Methode d'analyse en santé animale, PCR. Part 2. Exigences et recommandations pour le développement et la validation de la PCR en santé animale. XPU47-600-2. Afnor, La Plaine SaintDenis, France.

Atmar, R.L., Opekum, A.R., Gilger, M.A., Estes, M.K., Crawford, S.E., Neill, F.H., Ramani, S., Hill, H., Ferreira, J., Graham, D.Y. 2014. Determination of the 50\% human infectious dose for Norwalk virus. J. Inf. Dis. 209, 1016-1022.

Bisseux, M., Colombet, J., Mirand, A., Roque-Alfonso, A-M., Abranavel, F., Izopet, J., Archimbaud, 
C., Peigue-Lafeuille, H., Debroas, D., Bailly, J-L., Henquell, C. 2018. Monitoring human enteric viruses in wastewater and relevance to infections encountered in the clinical setting: a one-year experiment in central France, 2014 to 2015. Eurosurveillance 23, pii= 17-00237.

Boxman, I., Verhoef, L., Vennema, H., Ngui, S., Friesema, I.H., Whiteside, C., Lees, D., Koopmans, M. 2016. International linkage of two food-borne hepatitis A clusters through traceback of mussels, the Netherlands, 2012. Eurosurveillance 21, pii $=30113$.

Campos, C. J. A., Kershaw, S., Morgan, O.C., Lees, D.N. 2017. Risk factors for norovirus contamination of shellfish water catchments in England and Wales. Int. J. Food Microbiol. 241, $318-324$

De Graaf, M., van Beek, J., Koopmans, M.P.G. 2016. Human norovirus transmission and evolution in a changing world. Nat. Rev. 14, 421-433.

Di Girolamo, R., Liston, J. Matches, J. 1977. Ionic binding, the mechanism of viral uptake by shellfish mucus. Appl. Environ. Microbiol. 33, 19-25.

European Commission. 2017. Community Guide to the Principles of Good Practice for the Microbiological Classification and Monitoring of Bivalve Mollusc Production and Relaying Areas with regard to Regulation 854/2004. European Commission DG Health and Consumers. Issue 3.

FDA (2013). National Shellfish Sanitation Program (NSSP): Guide for the Control of Molluscan Shellfish. 2011 Revision. U. S. Department of Health and Human Services, Public Health Service, Food and Drug Administration.

Geoghegan, J., Senior, A.M., Di Giallonardo, F., Homes, E.C. 2016. Virological factors that increase the transmissibility of emerging human viruses. PNAS 113, 4170-4175.

Gerba, C., Betancourt, W.Q., Kitajima, M., Rock, C.M. 2018. Reducing uncertainty in estimating virus reduction by advanced water treatment process. Wat. Res. 133, 282-288.

Havelaar, A. H., Kirk, M.D., Torgerson, P.R., Gibb, H.J., Hald, T., Lake, R.J., Praet, N., Bellinger, D.C., de Silva, N.R., Gargouri, N., Speybroeck, N., Cawthorne, A., Mathers, C., Stein, C., Angulo, F.J., Devleesschauwer, B. 2015. World health organization global estimates and regional comparisons of the burden of foodborne disease in 2010. Plos Med 12, e1001923.

ISO/TS 15216-1. 2017. Microbiology of food and animal feed -horizontal method for determinaion of 
hepatitis A virus and norovirus in food using real-time RT-PCR, Part 1: method for quantification. ISO, Geneva, Switzerland.

Kittigul, L., Panjangampatthana, A., Rupprom, K., Pombubpa, K. 2014. Genetic diversity of rotavirus strains circulating in environmental water and bivalve shellfish in Thailand. Int. J. Environ. Res. Public Health 11, 1299-1311.

La Rosa, G., Sanseverino, I., Della Libera, S., Laconelli, M., Ferrero, V.E.V., Barra Caracciolo A., Lettieri, T. 2017. The impact of anthropogenic pressure on the virological quality of water from the Tiber river, Italy. Let. Appl. Microbiol. 65, 298-305.

Le Guyader, F. S., Loisy, F., Atmar, R.L., Hutson, A.M., Estes, M.K., Ruvoen-Clouet, N., Pommepuy, M., Le Pendu, J. 2006. Norwalk virus specific binding to oyster digestive tissues. Emerg. Infect. Dis. $12,931-936$.

Le Mennec, C., Parnaudeau, S., Rumebe, M., Le Saux, J-C., Piquet, J-C., Le Guyader, F.S. 2017. Follow-up of norovirus contamination in an oyster production area linked to repeated outbreaks. Food Environ. Virol. 9, 54-61.

Maalouf, H., Pommepuy, M., Le Guyader, F.S. 2010. Environmental conditions leading to shellfish contamination and related outbreaks. Food Environ. Virol. 2, 136-145.

McLeod, C., Hay, B., Grant, C., Greening, G, Day, D. 2009. Inactivation and elimination of human enteric viruses by Pacific oysters. J. Appl. Microbiol. 107, 1809-1818.

McLeod, C., Polo, D., Le Saux, J-C., Le Guyader, F.S. 2017. Depuration and relaying: a review on potential removal of norovirus from oysters. Comp. Rev. Food Sci. Food Saf. 16, 692-706.

Miura, T., Okabe, S., Nakahara, Y., Sano, D. 2015. Removal properties of human enteric viruses in a pilot-scale membrane bioreacror (MBR) process. Wat. Res. 75, 282-291.

Miura, T., Parnaudeau, S., Grodzki, M., Okabe, S., Atmar, R.L., Le Guyader, F.S. 2013. Environmental detection of genogroup I, II and IV noroviruses by using a generic real-time reverse transcription-PCR assay. Appl. Environ. Microbiol. 79, 6585-6592.

Miura, T., Schaeffer, J., Le Saux, J-C., Le Mehaute, Ph., Le Guyader, F.S. 2018. Virus type-specific removal in a full-scale membrane bioreact treatment process. Food Environ. Virol. https://doi.org /10.1007/s12560-017-9330-4 
Monedero, V., Buesa, J., Rodriguez-Diaz, J. 2018. The interactions between host glycobiology, bacterial microbiota, and viruses in the gut. Viruses 10, pii:E96.

Murphy, A.M., Grohmann, G.S., Christopher, P.J., Lopez, W.A., Davey, G.R., Millsom, R.H. 1979. An australian wide outbreak of gastroenteritis from oysters caused by Norwalk virus. Med. J. Australia. 2, 329-333.

Newton, R., McLellan, S.L., Dila, D.K., Vineis, J.H., Morrison, H.G., Eren, A.M., Sogin, M.L. 2015. Sewage reflects the microbiomes of human populations. mBio 6(2), e02574-02514.

Polo, D., Varela, M.F., Romalde, J.L. 2015. Detection and quantification of hepatitis A virus and norovirus in Spanish authorized shellfish harvesting areas. Int. J. Food Microbiol. 193, 43-50.

Pommepuy, M., Hervio-Heath, D., Caprais, M-P., Gourmelon, M., Le Saux, J-C., Le Guyader, F.S. 2005. Fecal contamination in coastal areas: an engineering approach. in: S. Belkin \& R. R. Colwell (Eds.), Oceans and health, pathogens in the marine environment (pp. 331-360). New York, NY: Springer.

Richards, G. P. 1988. Microbial purification of shellfish : a review of depuration and relaying. J. Food Protect. 51, 218-251.

Sano, D., Amarasiri, M., Hata, A., Watanabe, T., Katayama, H. 2016. Risk managment of viral infectious diseases in watewater reclamation. Environ. Int. 91, 220-229.

Sima, L.C., Schaeffer, J., Le Saux, J-C., Parnaudeau, S., Elimelech, M., Le Guyader, F.S. 2011. Calicivirus removal in a membrane bioreactor wastewater treatment plant. Appl. Environ. Microbiol. 77, 5170-5177.

Teunis, P.F.M., Sukhrie, F.H.A., Vennema, H., Bogerman, J., Beersma, M.F.C., Koopmans, M.P.G. 2015. Shedding of norovirus in symptomatic and asymptomatic infections. Epidemiol. Infect. 143, $1710-1717$.

Tian, P., Engelbrektson, A. L., Jiang, X., Zhong, W., Mandrell, R. E. 2007. Norovirus recognizes histoblood group antigens on gastrointestinal cells of clams, mussels, and oysters: a possible mechanism of bioaccumulation. J. Food Prot. 70, 2140-2147.

Ueki, Y., Shoji, M., Okimura, Y., Miyota, Y., Masago, Y., Oka, T., Katayama, K., Takeda, N., Noda, M., Miura, T., Sano, D., Omura, T. 2010. Detection of sapovirus in oysters. Microbiol. Immunol. 
$54,483-486$.

Uyttendaele, M., Jaykus, L-A., Amoah, P., Chiodini, A., Cunliffe, D., Jacxsens, L., Holvoet, K., Lorsten, L., Lau, M., McLure, P., Medema, G., Sampers, I., Jasti, P. R. 2015. Microbial hazards in irrigation water: standards, norms, and testing to manage use of water in fresh produce primary production. Comp. Rev. Food Sci. Food Saf. 14, 336-356.

Venugopal, V., Gopakumar, K. 2018. Shellfish: nutritive value, health benefits, and consumer safety. Comp. Rev. Food Sci. Food Saf. 16, 1219-1242.

Wang, H., Sikora, P., Rutgersson, C., Lindh, M., Brodin, T., Bjorlenius, B., Larsson, D.G.J., Norder, H. 2018. Differential removal of human pathogenic viruses from sewage by conventional and ozone treatments. Int. J. Hyg. Environ. Health. 221, 479-488.

Wang, J., Deng, Z. 2016. Modeling and prediction of oyster norovirus outbreaks along golf or Mexico coast. Environ. Health Perspect. 124, 627-633.

Wells, W.F. (1916). Artificial purification of oysters. Public Health Rep. 31, 1848-1852.

Yu, Y., Cai, H., Hu, L., Lei, R., Pan, Y., Yan, S., Wang, Y. 2015. Molecular epidemiology of oysterrelated human noroviruses and their global genetic diversity and temporal-geographical distribution from 1983 to 2014. Appl. Environ. Microbiol. 81, 7615-7624.

\section{Figure legend}

Figure 1 : Location of the sampling points in the estuary.

The red stars show the shellfish sample sites and the black arrow shows the sewage outfall location. 


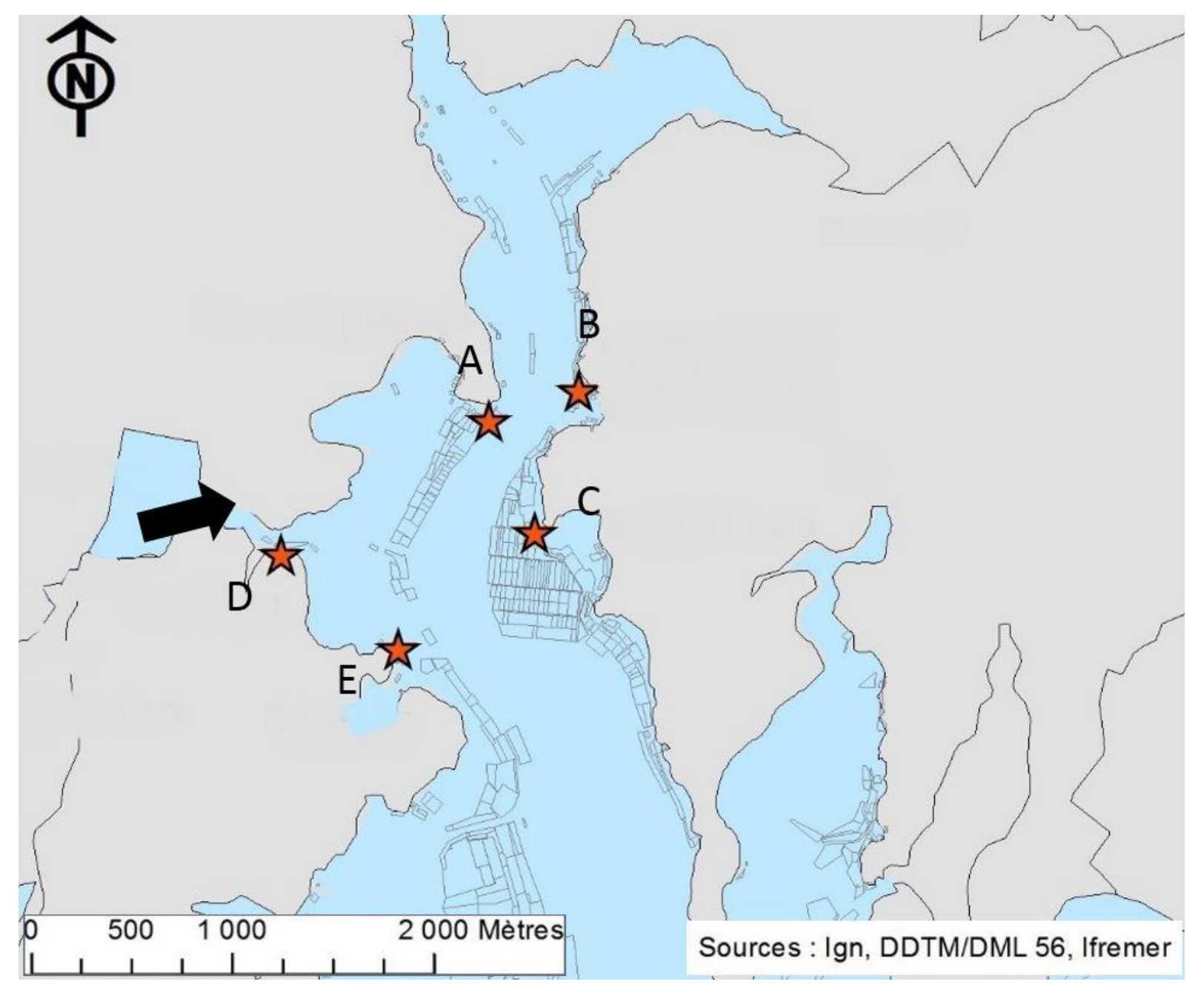


Table 1 : Detection of norovirus in water and oyster samples.

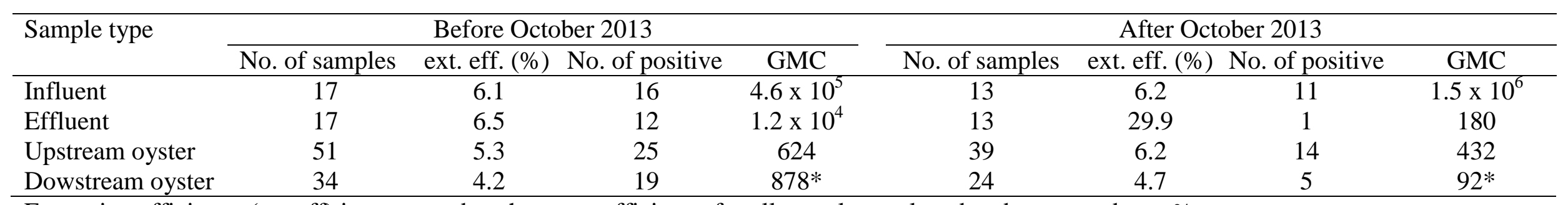

Extraction efficiency (ext.eff) is expressed as the mean efficiency for all samples analyzed and expressed as a $\%$.

Concentrations are expressed as the GMC (geometric mean concentration of all positive samples) of RNAc/L or g of DT, (or detected concentration when only one sample was positive).

* GMC detected in oyster samples collected downstream of the outfall of the sewage treatment plant were statistically different before and after October 2013. 